In three cases I did not remove the whole of the appendix owing to the risk involved; in two the tip of the appendix was incorporated with the rectum wall and I left the end implanted in the rectum; in one convalescence was protracted but eventually the patient became free from pelvic pain and has remained so for more than two years. In three cases I did not attempt to remove the appendix as it was surrounded by coils of small intestine so densely bound together that successful removal would have involved resection of intestine and a perilous dissection of the mass in order to liberate it from the sacrum and brim of the pelvis. In one of these patients an abscess subsequently formed which discharged into the rectum and was cured; the other two patients enjoy good health but for an occasional "bout of indigestion." I think it is better to let nature deal with such conditions than to perform dangerous and hazardous operations for which patients are not prepared. Patients prefer to put up with life in discomfort than to die victims to ultra-radical operations.

There is no royal road either as to the method of opening the abdomen or of removing the appendix, but in a large number of cases one can amputate the appendix through a two-inch skin incision and forcible entry by blunt dissection through the muscular planes but it often becomes necessary to enlarge the opening considerably in order to deal with unforeseen complications. Sometimes the complete operation can be performed with ease in ten minutes but usually it takes more than double that time and the last one I did (April 13th, 1905) took one and a half hours. The Trendelenburg position is of great value in cases where the appendix is situated in the pelvis ; in these cases it is usually easier to remove the appendix by starting from above by severing it from the cæcum and then continue the dissection downwards towards the tip. I adopt the same course in cases where there is no meso-appendix and where the end of the appendix is tied down. This method is also preferable in cases where the base of the appendix is healtby and its end has a pearshaped enlargement (see Fig. 3). In all other conditions of

FIG. 3.

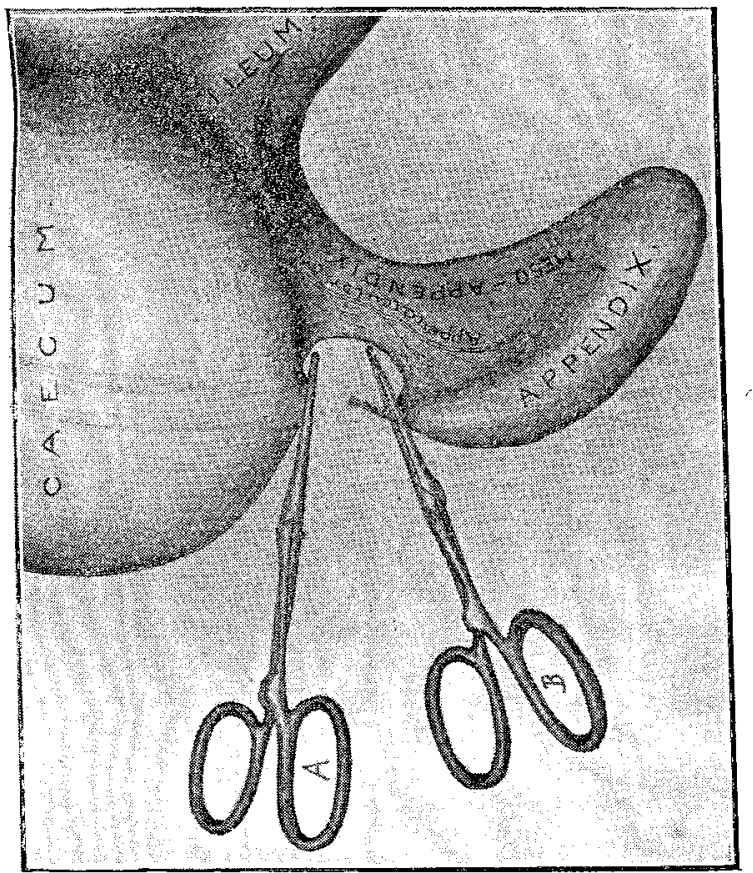

To show that when the appendix is in the pelvis, or has no meso-appendix, the first step is to crush its attachment to the cxerm and to apply two pairs of forceps to the crushed part which is then cauterised or cut flush along forceps $A$.

the appendix it is easier to start at the free end and work towards its attachment to the cæcum. On occasions where the diseased appendix resembles an icicle in relation to its attachment to the cæcum it is occasionally necessary to remove a small piece of the cxcal wall in order to get a suitable stump. It has not been my fortune in most of the cases to be able to perform an ideally simple method of dealing with the stump of the appendix-i.e. crush it at its creal attachment and apply two pairs of narrow-bladed forceps to the crushed part and either burn off or cut off along the forceps attached to the cæcum, then tie and invaginate by either a purse-string or interrupted suture. I find a serrated crushing forceps far superior to a smooth one owing to its obliterating effect upon the bloodvessels.

No matter what method is used in treating the stump it is not only desirable but always necessary to bring the peritoneum over raw surfaces whenever possible, as post-operative complications in after years can only be avcided by careful attention to these details. A patient who was operated upon by a well-known surgeon in 1890 and to whom I administered the anæsthetic died last year from acute strangulation due to a coil of intestine being incarcerated under a band extending from the end of the cæcum to the abdominal wall. The base of the appendix was simply tied and cut off after the early fashion of dealing with an ovarian pedicle. When the stump cannot be covered with the peritoneum the end of the crecum can usually be fixed to the abdominal wall by points of sutures or omental flaps applied to it.

In cases of retrocæcal position of the appendix great care should always be taken to close accurately by suture the incision made through the peritoneum for its exposure, as a complication occurred within 12 months of appendicectomy in one of my cases which $I$ am not aware of having been previously recorded. In February, 1900, I removed a retrocæcal appendix containing pus and I allowed the cæcum to fall back into its natural position after the operation. In time the patient began to lose flesh and complained of dragging pain in the region of his stomach. He consulted Sir Lauder Brunton and was advised to undergo operation in order to deal with some mechanical obstruction to the passage of food from the stomach. I operated and found that the great omentum had got fixed into the retrocæcal space made for the removal of the appendix. I divided the great omentum, which dragged upon the transverse colon and stomach, and the patient was kept lying on his left side for some days after operation in order that the divided surfaces of the omentum should be kept well apart during the process of repair. Since that experience I carefully close all incisions made in the peritoneum and if drainage of the retrocæcal space is thought advisable it can be done extraperitoneally by extending the parietal incision upwards and backwards parallel with the crest of the ilium and an inch above it.

Cardiff.

\section{FAMILY TABES DORSALIS: TABES IN HUSBAND, WIFE, AND DAUGHTER. ${ }^{1}$}

By E. F. TREVELYAN, M.D., B.Sc. LOND. F.R.C.P. LOND,

PHYSICIAN (WITH CHARGE OF OUT-PATIENTS) TO THE LEFDS GENERAI INFIRMART.

IN 1898 I recorded an instance of conjugal tabes dorsalis ${ }^{2}$ of which the main details were as follows. The man, aged 58 years, married at 22 years of age and showed early $\$$ ymptoms of tabes at the age of 33 years. In 1898 the pupils did not react to light and the knee-jerks were absent. There was marked incoördination in the legs in consequence of which he was bedridden. There were characteristic pains and bladder symptoms. He had had a passing hemiplegia a year previously. The woman, aged 55 years, married at 19 years of age and developed the early symptoms of tabes at the age of 29 years. In 1898 the pupils were very small and did not react to light. She suffered from pains, attacks of vomiting, and bladder symptoms. The left tibia had fractured spontaneously and both knees were swollen from tabetic arthropathy. The question of past syphilis could not be thoroughly investigated in this tabetic couple, but the family history (to be given later) and the occurrence of the tabes itself made syphilis practically certain.

Since the date mentioned above the man has died, aged 58 years. The wife remains in much the same state, the disease being almost, if not quite, stationary. She has occasional pains and bladder symptoms, but she is able to earn money by sewing. The eldest daughter now presents well-marked symptoms of tabes. In 1898 I strongly suspected that she was commencing with the disease owing to

I A paper read before the Neurological Society on May 18th, 1905. Trevelyan: Brit. Med. Jour., vol. ii., 1898. 
the presence of pains. Since then I have watched the pupil reflex gradually (but with variations) diminish and disappear, and also the knee-jerks become less and eventually go altogether, the left disappearing first. The following are the clinical details of this case.

The patient, aged 43 years, commenced to have pains and occasional double vision when she was 36 years of age. She also complained of some difficulty in getting up and down stairs. A feeling of constriction round the body was noticed a little later and occasionally she had slight bladder disturbance. Present condition (May, 1905). The patient is distinctly neurotic but otherwise there are no mental symptoms. The pupils are small (one and a half millimetres) and equal but they do not react to light. A perceptible reaction occurs to accommodation. There is no affection of the eye muscles, no optic atrophy, and no choroiditis. There is some incoordination in the legs, especially in the left, and she sways a little when standing with the eyes closed and the feet together, but this incoördination is very slight. There is a zone of hyperæsthesia round the trunk on a level with the eighth and ninth dorsal vertebræ. There is no knee or tendo Achillis jerk. The plantar reflex is flexor in type. There is no bladder disturbance at the present time.

The family history of this tabetic couple is of considerable interest. 'There have been 12 pregnancies and of nine children born alive only one was a boy. Only three of these children are still living. The following is an account of the results of the 12 pregnancies: 1. A girl, now aged 43 years (tabetic); married (for family see later). 2. A boy, died, aged 15 years, from rheumatic fever and cardiac disease. 3. A girl, now aged 38 years, quite well; married: ten children (nine living, three miscarriages). 4. A girl, died, aged 14 months. 5. A girl, died, aged 23 years, from puerperal fever. She also had rheumatism and heart disease. (The first symptoms of tabes appeared in the wife about this time). 6. A girl, died, aged four and a half years, from inflammation of the brain. 7. A girl, died, aged 15 months. 8. A miscarriage. 9. A miscarriage (probably a macerated fœetus). 10. Born dead at term. 11. A girl, now aged 26 years, unmarried. She has had rheumatism and heart disease. 12. A girl, died, aged 14 months. The last half of that family was strikingly and curiously worse than the first half.

The usual history of the syphilitic family such as that related by Pourreyon ${ }^{3}$ in a tabetic couple may be given for contrast. There were five pregnancies : (1) a miscarriage at four and a half months; (2) a miscarriage at six months ; (3) a miscarriage at seven months; (4) born at term, died aged four months (tabetic pains appeared in the wife); and (5) living and well.

As has been mentioned, no satisfactory evidence of past syphilis is forthcoming in my tabetic pair except such as is derived from the family history. Before his marriage the man had been a sailor and perhaps for this reason sypnilis is not very improbable. It was known that the husband and wife were a hard-working, steady, and industrious couple. The history of the daughter's family is also important. There bave been six pregnancies. 1. A boy, died, aged five years, from inflammation of the brain, probably tuberculous. 2. A girl, aged 14 years, alive and well. 3. A miscarriage. 4. A girl, aged 11 years, alive and well. 5. A girl, aged eight years. This child is said to have had snuffles when six months old but there were no other symptoms. This and the next child have been examined and no evldence of congenital syphilis can be made out in them. 6. A girl, aged four years, alive and well. The daughter's husband is a healthy man who denies having had venereal disease and no signs of past syphilis can be found on him. The daughter herself also presents no history or evidence of acquired syphilis. She also shows no signs of congenital syphilis but the upper teeth have decayed away. I conclude that this tabetic couple almost certainly had syphilis and that there is no evidence to show the existence of acquired syphilis in the tabetic daughter and her husband.

I propose to make a few remarks on conjugal tabes, on tabes in both parents and offspring, on tabes in one parent and offspring, and also upon the relationship between congenital syphilis and tâbes. While admitting the very strong evidence of the identity of the morbid entity in tabes and general paralysis, I shall only refer incidentally to the latter affection. Little need be said about conjugal tabes, for much has been written about it during the past few years, and series of cases have been collected and added to by various writers. The percentage of syphilis in them is given by Hudovernig ${ }^{4}$ as 96 and by Raecke ${ }^{5}$ as 90 . It may be of interest to refer to an instance of conjugal tabes in pure negroes which was reported by Francine ${ }^{6}$ because syphilis is common and tabes apparently very rare among negroes. Usually the disease begins in the husband first and the wife develops symptoms in the course of from two to five years, or even ten years, and in one case 20 years afterwards. In my couple the disease began first in the wife and the interval before the appearance of the symptoms in the husband was one and a half years. It is also noteworthy that if general paralysis takes the place of tabes in the affected couple it usually attacks the husband, the wife being tabetic.

Tabes in both husband, wife, and offspring.-This combination seems to be very exceptional. I have only been able to find one or two instances of it. Max Nonne ${ }^{\top}$ records a remarkable instance in which all three were infected extragenitally. The child was infected with syphilis by a boy bedfellow and he in turn infected his parents. All three became tabetic, the boy devoloping tabes five years after the time when he was infected. The same author ${ }^{8}$ also refers very briefly to an instance in which both the syphilitic father and the mother became tabetic and the boy was feeble-minded and tabetic. It may, of course, with Grompert $z^{9}$ be objected in such cases that the affection in the boy was more in the nature of a genuine spphilitic lesion rather than tabes. Dr Dawson F. D. Turner ${ }^{10}$ recorded a group of cases in which both husband and wife had tabes and their child presented several symptoms belonging, not to tabes, but to Friedreich's ataxia. This child also had aortic disease.

There are instances in which general paralysis has taken the place of tabes in one or more of the individuals of the group under consideration. Thus in a remarkable instance related by Souques ${ }^{11}$ the husband was syphilitic and a general paralytic and the wife and two daughters tabetic. In Kutner's ${ }^{12}$ group the father was syphilitic and a general paralytic, the wife tabetic, and the daughter, 13 years of age, also tabetic for the past three years. Or, again, the cases of Moenkmoeller, ${ }^{13}$ in which the father had tabes and the mother and daughter general paralysis.

To illustrate the importance of the relationship of syphilis to tabes (and general paralysis) the groups of cases recorded by Erb, ${ }^{14}$ Finkelburg, ${ }^{25}$ and Wertheimer ${ }^{16}$ may be referred to in which tabes or general paralysis was present in two of the individuals and syphilis of the nervous system in the third. Finally, to complete the series, in the instance related by Arning ${ }^{17}$ (quoted by $\mathrm{Erb}^{18}$ ) all three individuals-viz., husband, wife, and offspring-developed signs of cerebral syphilis.

Tabes in one parent and offspring.-These cases are fairly numerous. Remak, ${ }^{18}$ Berbez, ${ }^{20}$ Erb, ${ }^{21}$ Golaflam, ${ }^{22}$ Kahlischer, ${ }^{23}$ Dydynski, ${ }^{24}$ Brasch, ${ }^{25}$ Babinski, ${ }^{26}$ Max Nonne, ${ }^{27}$ and others have recorded instances of it. A daughter seems to be more frequently affected than a son. Congenital syphilis is the all-important factor in these cases as far as the offspring is concerned, but acquired syphilis may be the cause, as in Max Nonne's ${ }^{24}$ case, and also in Kron's ${ }^{29}$ case where a child infected from a nurse developed tabes at the age of 13 years. The disease usually appears at the age of five years or upwards, the cases falling into the group of infantile or juvenile tabes. The daughter of my tabetic

4 Hudovernig : Neurologisches Centralblatt, 1903.

5 Raecke, quoted by Erb : Berliner Klinische Wochenschrift, 1904

Francine : American Journal of the Medical Sciences, 1900. Nonne: Fortschritt der Medicin, 1904

Nonne : Berliner Klinische Wochenschrift, 1904

Gompertz: Neurologisches Centralblatt, 1900

10 Turner : THE LaNCET, Nov. 1st, 1890, p. 920

(1902.

12 Kutner: Allgemeine Zeitschrift fur Psychiatrie, 1960

13 Moenkmoeller, quoted by Mott : Archives of Neurology, vol. ii.

14 Firb: Berliner Klinische Wochenschrift, 1904.

I5 Finkelburg. Deutsche Zeitschrift fir Nervenheilkunde, Bände v. und vi.

16 Wertheimer: Neurologisches Centralblatt, 1904 (abstract).

17 Arning, quoted by Erb : Berliner Klinische Wochenschrift, 1 cot.

18 Erb : Loc. cit

ou Berbez. Pronres Médical, 1887 .

2t Wrb : Deutsche Medicinische Woehenschrift, 1891

22 Goldflam: Deutsche Zeitschrift fur Nervenheilkunde, 1892.

23 Kahlischer : Berliner Klinische Wochenschrift. 1898

24 Dydynski : Neurologisches Centralblatt. 1900

28 Babinski : Bulletin de la Société des Hopitaux, 1902

27 Nonne: Berliner Klinische Wochensthrift, 1904. 28 Ibid.

29 Kron : Neurologisches Centralblatt, 1901. 
couple developed tabes in her thirty-seventh year-a late date for tabes to develop on a congenital syphilitic basis. It is also true that we found no marks of congenital syphilis upon her and there is only the evidence provided by her family in favour of congenital syphilis.

It is not, however, absolutely necessary for the purpose in question that the patient should bear the usual stigmata of congenital syphilis-indeed, some go so far as to look upon the tabes itself as a stigma of late hereditary syphilisand on the other hand, I think we have fairly excluded acquired syphilis. It is interesting to note that in the case of a tabetic woman, aged 22 years, bearing the stigmata of congenital syphilis, Barthelemy ${ }^{30}$ deliberately assigns the tabes to congenital syphilis although the patient had been abun. dantly exposed to the infection of acquired syphilis but had not had any of its usual manifestations. Quite apart from the subject of tabetic couples and their offspring, a fair number of cases are on record in which adult tabes has been attributed to congenital syphilis. Usually the disease has commenced before 20 years of age but in some cases considerably later. Thus Max Nonne ${ }^{31}$ quotes a case of tabes in a man aged 32 years, who had suffered from severe lightning pains for two years and who had never been infected with syphilis or addicted to drink. The patient had previously been treated for congenital syphilis and Nonne looks upon the latter as the cause of the tabes in this case. Sabrazes ${ }^{32}$ has also reported a most interesting case in a man, aged 42 years, in whom the tabes appeared two years previously. In the absence of a history of acquired syphilis and in the presence of marked stigmata of congenital syphilis the autbor assigns the latter as the cause of the tabes. Pourreyon ${ }^{33}$ in his interesting thesis concludes that when tabes or general paralysis is of congenital syphilitic origin it begins at an age between five and 40 years and he adds that these cases are interesting for the study of precocious or late congenital syphilis. Dydynski ${ }^{31}$ even goes so far as to say that if observers do not lose sight of congenital syphilis fewer cases of tabes will be recorded where syphilis has been excluded.

The question, it seems to me, may be put in this form in my cases. Did the tabetic couple merely hand down to their daughter a general vulnerability of nervous tissue to certain noxæ (whether in the form of the syphilitic virus or of stress, strain, \&c.), or did they transmit to her the actual virus which would bring about with little or no further provocation the eventual degeneration of the afferent sensory neuron?-and I should answer it in the latter sense. Kahlischer ${ }^{35}$ has related an instance of tabes in mother and son, the tabes appearing at the age of 26 years in the latter. He excludes to his satisfaction both congenital and acquired syphilis and he attributes the tabes almost solely to congenital hereditary influences. This question of neuropathic heredity in tabes (and general paralysis), at one time much emphasised by the French school, is no longer looked upon as of any very great importance. Yet there have been series of cases recorded where the neuropathic heredity has been marked. Thus Berbez ${ }^{36}$ as long ago as 1887 mentioned that among 150 cases of tabes there was a neuropathic heredity in 63 and tabes or general paralysis in a parent in 15 of these cases. Dydynski ${ }^{37}$ in 1890 , in speaking of infantile tabes (and at that time he would only allow seven such cases), found besides congenital syphilis a neuropathic heredity in six. Probably this neuropathic heredity can only mean a greater vulnerability of the nervous system to the causes of tabes such as the syphilitic virus. It is well seen in cases where, for instance, brothers infected with syphilis from different sources (Erb, Max Nonne, and others) have developed tabes. Among my cases I have records of two brothers, one of whom was suffering from tabes when the other developed an acute general paralysis with fits and died within the year. Apart from this vulnerability of the nervous system, it should, no doubt, be remembered that the syphilitic virus may sometimes be of great potency so far as the nervous system is concerned. This is well exemplified when two or more individuals contract syphilis from the same source

${ }^{30}$ Barthelemy : Annales de Dermatologie et de Syphiligraphie, 1867.

32 Sabrazes : Nouvelle Iconographie de la Salpêtrière, 1903.

33 Pourreyon: Loc. cit.

3 t Dydynski : Loc. cit.

Kahlischer: Loc. eit.

37 Dydynski : Loc, cit as in the cases of Erh, ${ }^{38}$ Max Nonne, ${ }^{39}$ and Marie et Bernard, ${ }^{40}$ and all, or nearly all, ultimately develop tabes (or general paralysis), or again in the truly appalling instance related by Brosius ${ }^{41}$ where out of seven glass-blowers infected with syphilis from the same source one developed tabes, another tabo-paralysis, and two others general paralrsis. As far as the neuropathic heredity is concerned it would appear to be correct to look upon it with Fehre ${ }^{42}$ as nothing more than a predisposing cause and probably not as a very important one.

I have to thank Dr. P. G. Steele, the resident medical officer at the Leeds General Infirmary, and Dr. B. Suggit of the Leeds Public Dispensary for assistance in getting together notes and histories of my cases.

Leeds.

\section{A SIMPLE TECHNIQUE FOR THE BAC- TERIOSCOPIC EXAMINATION OF SEWAGE.}

\author{
By W. H. C. FORSTER, M.B., O.M. EDIN., \\ D.P.H. Cantab.,
} CAPTAIN, I Ir.s.

(From the Laboratory of the Pasteur. Institute of India, Kasauli.)

From the point of view of the laboratory worker in the East the methods at present in vogue for the quantitative estimation of the "organisms of indication" in sewage leave much to be desired. These methods all presuppose the ice packing of samples when necessary and the existence of a laboratory well stocked with the particular apparatus required-preliminary conditions which do not often obtain in India. Thus it has come to pass that although biological methods for the treatment of sewage have been making steady headway in India for some years past, official and public records are silent on the bacteriological side of the question. It will, I think, be readily admitted that, in the interests of the public health, every biological method for the disposal of sewage should be made the subject of systematic bacterioscopic examination. It is unlikely, however, that this will ever be the case whilst our present methods of investigation remain unaltered. A brief survey of some of the methods at present employed in the bacterioscopic examination of sewage will serve to make the point clear. The criteria usually adopted in the examination of sewage are four in number: (1) the total number of organisms per cubic centimetre; (2) the number of bacillus coli per cubic centimetre; (3) the number of streptococci per cubic centimetre; and (4) the number of spores of bacillus enteritidis sporogenes per cubic centimetre. For the purpose of demonstrating the cumbersomeness of the methods of estimation usually employed it will be sufficient if we indicate only those available for the quantitative estimation of bacillus coli and the spores of bacillus enteritidis sporogenes.

The methods of estimating bacillus coli.-1. By the microscopic examination of colonies developing from surface cultivations on phenolated gelatine or agar plates. These cultivations are made either directly from the material to be examined or from preliminary phenol broth cultures. This method is extremely laborious and even in the most practised hands leaves much to be desired in the way of accuracy. 2. By the neutral-red broth method. 3. By MacCorkey's method. 4. By Pakes's method. 5. By Houston's method.

Method of estimating the spores of bacillus enteritidis sporo. genes. - The only practicable method is by the use of milk cultures heated to $80^{\circ} \mathrm{C}$. for 15 minutes and incubated anaerobically at $37^{\circ} \mathrm{C}$.

Whichever method of enumerating bacillus coli the routine worker may adopt he has to face the difficulties of ice packing and apparatus. For example, let us suppose that a sewage-disposal system consisting of an open septic tank and a couple of continuous filters is the subject of

38 Erb: Berliner Klinische Wochenschrift, 1904.

Marie et Dernard: Deutsche Zeitschrift fur Nervenheilkunde, 1897.

41 Brosius : Archiv für Psychiatrie. Band xxxvii., 1923

$\checkmark 2$ Fehre : Berliner Klinsche Wochenschrift, 1901 . 